\title{
Cost-Effectiveness of Helicopter Transport of Stroke Patients for Thrombolysis
}

\author{
Robert Silbergleit, MD, Phillip A. Scott, MD, Mark J. Lowell, MD, \\ Richard Silbergleit, MD, MBA
}

\begin{abstract}
Objectives: Treatment with intravenous (IV) or intra-arterial (IA) thrombolysis in patients with acute ischemic stroke demands careful patient selection and specialized institutional capabilities. Physicians at hospitals without these resources may prefer patient transfer for acute treatment. Helicopter transport for these patients has been described but without analysis of the effects of its additional cost. The authors examined the cost-effectiveness of helicopter transport for patients with acute stroke. Methods: Costs per additional good outcome and per quality-adjusted life-year (QALY) were calculated using a computer model. Input variables included flight, thrombolytic agent, and angiography costs; annual cost per patient for long-term care of symptomatic stroke; percentage of transported patients treated; percentage of patients receiving IV versus IA therapy; discount rate; absolute probability of good outcome; annual mortality with and without treatment; and

quality-of-life modifier. Sensitivity analysis was performed. Results: Helicopter transport of acute stroke patients to tertiary care centers for thrombolytic therapy costs $\$ 35,000$ per additional good outcome and $\$ 3,700$ per QALY for the reference case. Cost-effectiveness was sensitive to the effectiveness of thrombolysis but minimally sensitive to most other input values. Cost per QALY ranged from $\$ 0$ to $\$ 50,000$, as the absolute increase in good outcomes (minimal or no deficit) ranged from $20 \%$ to $5 \%$. Cost-effectiveness was not sensitive to ranges of helicopter flight costs or the proportion of flown patients undergoing treatment. Conclusions: This model indicates helicopter transfer of patients with suspected acute ischemic stroke for potential thrombolysis is cost-effective for a wide range of system variables. Key words: aircraft; cost-effectiveness analysis; fibrinolytic agents; stroke. ACADEMIC EMERGENCY MEDICINE 2003; 10:966-972.
\end{abstract}

The importance of emergency medical services (EMS) in the care of patients with acute ischemic stroke has increased with the development of time-limited reperfusion therapies, including intravenous (IV) ${ }^{1}$ and intra-arterial (IA) thrombolysis. ${ }^{2,3}$ Studies of outof-hospital stroke care have focused on the abilities of emergency medical technicians to identify the signs and symptoms of stroke and accelerate transport of the patient to the emergency department, ${ }^{4-7}$ but thrombolytic treatment of stroke requires expertise and resources not available at all hospitals to which patients arrive via ground ambulance. Patients taken to facilities without acute treatment capability may require emergent transfer to tertiary centers.

From the Department of Emergency Medicine and Survival Flight, University of Michigan (RS, PAS, MJL), Ann Arbor, MI; and Department of Diagnostic Radiology, William Beaumont Hospital (RS), Royal Oak, MI.

Received August 21, 2002; revision received March 11, 2003; accepted March 17, 2003.

Presented in part at the Annual Meeting of the National Association of EMS Physicians, January 2000, Marco Island, FL, and at the International Society for Thrombolytic Therapy, November 2000, Hamilton Island, Queensland, Australia.

Address for correspondence and reprints: Robert Silbergleit, MD, Department of Emergency Medicine, University of Michigan, TC B1354/0303, 1500 East Medical Center Drive, Ann Arbor, MI 481090303. Fax: 734-936-9414; e-mail: robie@umich.edu.

doi:10.1197/S1069-6563(03)00316-6
Helicopter air medical transport is often the most rapid and effective means of accomplishing these interfacility patient transfers and extends the geographic reach of specialized treatment centers. An important role for air medical transport of acute stroke patients was anticipated at the 1997 National Institutes of Health conference on implementing the results of the National Institute of Neurological Disorders and Stroke (NINDS) recombinant tissue plasminogen activator (rt-PA) study. ${ }^{8}$ The importance of using EMS to get patients to specialized stroke care was emphasized again in a set of consensus-derived guidelines. ${ }^{9}$

Several institutions currently are using helicopter air medial services for this purpose. Articles describing the experiences of flight programs at the University of Pennsylvania and the University of Cincinnati have reported that flying acute stroke patients is feasible, safe, and potentially beneficial. ${ }^{10,11}$ Other stroke teams and flight programs have presented their experiences in abstract form with similar conclusions. The experiences of these programs suggest acute stroke transports by air medical services can be performed, but do little to help determine if they should be performed. Helicopter transport is an expensive and limited resource, and to our knowledge the question of cost-effectiveness of air medical transfer of patients with acute stroke has not been addressed previously. 
In other settings, air medical transport appears economically viable. Gearhart et al. ${ }^{12}$ showed helicopter transport was cost-effective in trauma patients, and the variables under which helicopter transport of patients with acute myocardial infarction for primary angioplasty can be cost-effective have been identified. ${ }^{13}$ The cost-effectiveness of air medical transfer for stroke treatment may be different, however, because rt-PA and angiography are expensive therapies even before the cost of helicopter transport is considered. Furthermore, it may be difficult to effectively select patients for transport to ensure subsequent eligibility for thrombolysis after arrival at a receiving hospital capable of providing thrombolytic therapy. The transport of patients not meeting treatment criteria would generate substantial medical costs without prospects for patient or societal benefit. Fagan et al. ${ }^{14}$ previously found IV thrombolytic treatment of stroke within three hours of onset to be cost-effective, but the analysis did not include transport costs or potential IA treatment. The objective of this study was to evaluate the cost-effectiveness of using helicopter air medical services to transport patients with acute stroke to a tertiary center prepared to provide thrombolysis (IV or IA) within six hours of symptom onset.

\section{METHODS}

Study Design. This analysis uses a cost-effectiveness model developed and reported following consensus guidelines for medical cost-effectiveness research derived by a panel convened by the Public Health Service. ${ }^{15}$ We also have attempted to use the best methods consistent with previous stroke-related costeffectiveness research as reported by Holloway et al. ${ }^{16}$ A linear computer model was developed in a spreadsheet program (Excel; Microsoft Corp., Redmond, WA). The intervention studied was transport followed by treatment with IV thrombolysis, IA thrombolysis, or no thrombolysis. The alternative to the intervention was nontransport with no thrombolysis. Patient event pathways in the model are illustrated in Figure 1. The complete model is described mathematically in the Appendix. Conceptually the model is defined by three sets of parameters: reference population, health care outcomes, and health care costs.

Study Setting and Population. The reference population refers to the assumptions made regarding the

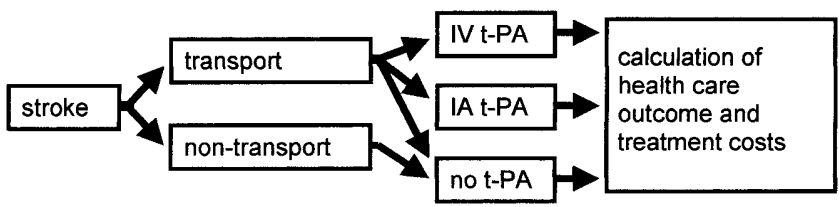

Figure 1. Patient event pathways in the linear cost-effectiveness model. IV = intravenous; IA = intra-arterial; t-PA = tissue plasminogen activator. characteristics of the patients in the model. The reference population used in this study represents the patients included in the NINDS and Prourokinase in Acute Thrombo-embolic Stroke (PROACT) trials ${ }^{1,3}$ and are patients with acute ischemic stroke with a mean age $( \pm \mathrm{SD})$ of $65 \pm 12$ years. We estimate that preflight screening of requested transfers can be effective enough such that $65 \%$ of patients transported would be eligible for treatment. ${ }^{4,17}$ The data of Conroy et al. $^{11}$ indicate that $38 \%$ of patients would be transported in the 0- to 3-hour window and $62 \%$ in the 3- to 6-hour period.

\section{Study Protocol}

Health Care Outcomes. The parameters of the model included in the health care outcomes portion of the analysis refer to the choice of how effectiveness is measured and the assumptions made about how well the treatment works. Effectiveness is described by the frequency of good outcome at 3 months and by quality-adjusted life-years (QALYs). Frequency of good outcome at 3 months is the most widely used stroke outcome measure and is defined as minimal or no disability as determined by a modified Rankin score of 0 or 1 at 90 days after the onset of symptoms. This measure does not allow comparison of cost-effectiveness for diseases other than stroke. The most widely used measure for cost-effectiveness is the QALY. This measure allows comparison with other medical interventions and health care conditions. Derdeyn and Powers ${ }^{18}$ derived a quality-of-life factor of 0.66 from prior surveys of symptomatic stroke patients. These patients reported that, if possible, they would be willing to trade 10 years of life with their disability for 6.6 years of life without disability from their stroke. ${ }^{18}$

The effectiveness of treatment is based on the results of the NINDS and PROACT trials, ${ }^{1,3}$ which are summarized in Table 1 . For the reference case in this model, we selected an absolute improvement of $13 \%$ for IV thrombolysis between zero and three hours and 9\% for IA thrombolysis between three and six hours. The frequency of good outcome without treatment was assumed to be $20 \%$ based on the NINDS placebo group. We used a combined absolute mortality improvement of $3 \%$ at one year based on the trends identified in the thrombolytic trials. Subsequent mortality was assumed to be unaffected by treatment and constant at $10 \%$ per year.

Health Care Costs. When asking about health care costs, the first question is "cost to whom?" This is termed the perspective of the cost-effectiveness analysis. We used a consensus "broad health care system" perspective. This includes acute and long-term direct care costs but excludes other costs of disability, such as lost productivity. Costs are those accrued over the 
TABLE 1. Outcome Data Summarized from the NINDS Trial ${ }^{1}$ of Intravenous Tissue Plasminogen Activator and the PROACT II Trial of Intra-arterial (IA) Prourokinase ${ }^{3 *}$

\begin{tabular}{lcccccc}
\hline & Route & $\begin{array}{c}\text { Treatment } \\
\text { Group (\%) }\end{array}$ & $\begin{array}{c}\text { Placebo } \\
\text { Group (\%) }\end{array}$ & $\begin{array}{c}\text { Relative } \\
\text { Effect (\%) }\end{array}$ & $\begin{array}{c}\text { Absolute } \\
\text { Effect (\%) }\end{array}$ & $\begin{array}{c}\text { Reference } \\
\text { Selected (\%) }\end{array}$ \\
\hline Good outcome (mRS <2) & IV & 39 & 26 & 50 & 13 & 13 \\
Mortality & IA & 26 & 17 & 53 & 9 & 9 \\
& IV & 17 & 21 & 19 & 4 & 3 \\
\hline
\end{tabular}

*The far right column shows the values selected for use in the reference case, which is the absolute effectiveness for each route for frequency of good outcome and an average of the absolute effectiveness of each route for mortality (to simplify the model). NINDS = National Institute of Neurological Disorders and Stroke; PROACT = Prourokinase in Acute Thrombo-embolic Stroke; mRS = modified Rankin score.

remaining life of the patient discounted at $5 \%$ annually. Accrued financial benefits also are discounted.

Flight costs per patient were derived by dividing the total cost of running the University of Michigan air medical service, Survival Flight, in fiscal year 1998 by the number of helicopter patient transports completed. Average costs per patient were used to prevent bias that may occur if only incremental costs were used in the analysis. Our cost of $\$ 3,749$ per patient is typical according to informal data collected by the Association of Air Medical Services (Landis D. personal communication, 2000), although slightly higher than flight costs reported by Gearhart et al. ${ }^{12}$ for the Pennsylvania State University flight service Life Lion (Table 2). We used an rt-PA (alteplase) acquisition cost of $\$ 2,500$ per patient as reported by Fagan et al. ${ }^{14}$ and estimated angiography costs of $\$ 4,000$ per patient. The reported average long-term care costs for patients with acute stroke ranges from $\$ 10,000$ to $\$ 50,000$ per year. ${ }^{14,18,19}$ We used a conservative estimate of $\$ 15,000$ per year for average longterm care costs for the model. Other routine health care costs are not included in any arm of the model because they cancel out when the cost for one alternative is subtracted from another.

\begin{tabular}{|c|c|c|}
\hline & $\begin{array}{c}\text { Life Lion } \\
\text { FY94-95 } \\
\text { (Gearhart) }^{12}\end{array}$ & $\begin{array}{c}\text { Survival } \\
\text { Flight FY98-99 } \\
\text { (our data) }\end{array}$ \\
\hline Personnel & $\$ 1,197,115$ & $\$ 1,727,520$ \\
\hline Capital expenses & $\$ 491,081$ & $\$ 911,878$ \\
\hline Operations & $\$ 296,796$ & $\$ 1,644,927$ \\
\hline Administration & $\$ 118,332$ & $\$ 114,949$ \\
\hline Insurance & $\$ 134,942$ & $\$ 213,249$ \\
\hline Medical supplie & $\$ 15,685$ & $\$ 149,001$ \\
\hline Total operating expense & $\$ 2,253,951$ & $\$ 4,761,524$ \\
\hline Helicopter patient transports & 1,018 & 1,270 \\
\hline Average cost/patient flight & $\$ 2,214$ & $\$ 3,749$ \\
\hline
\end{tabular}

*The higher estimate, shown at the bottom of the right-hand column, was selected for use in the reference case.

$\mathrm{FY}=$ fiscal year.
Data Analysis. We performed a primary sensitivity analysis by varying our assumptions on effectiveness, flight costs, percent of patients eligible for treatment after arrival, and distribution of patients to IV versus IA routes of drug delivery. We also performed a secondary sensitivity analysis on other input factors, including long-term care costs, which were not immediately related to thrombolytic therapy or patient transport but had potentially large effects on the model.

\section{RESULTS}

Analysis of this model shows that air medical transport of stroke patients for thrombolysis is costeffective. For the reference case, this intervention cost $\$ 35,000$ per additional good outcome and $\$ 6,100$ per QALY.

Cost-effectiveness is sensitive to assumptions regarding treatment effectiveness but is relatively insensitive to a wide range of other assumptions. Sensitivity to the magnitude of effectiveness is shown in Figure 2, in which cost per additional good outcome is shown on the vertical axis and magnitude of effectiveness is shown on the horizontal axis. The three components of effectiveness used in the model (absolute \% increase in good outcome from IV thrombolysis, absolute \% increase in good outcome from IA thrombolysis, and absolute \% improvement in mortality) range linearly together from zero effectiveness on the left side to substantial effectiveness on the right. The horizontal and vertical plotted lines indicate the cost per additional good outcome in the reference case, where mortality is $3 \%$ and effectiveness is $13 \%$ for IV and $9 \%$ for IA. The curve resulting from the model shows costs rising as effectiveness diminishes and savings rising as effectiveness increases. Figure $2 \mathrm{~A}$ shows the sensitivity to effectiveness alone in the reference case. Additional elements of the sensitivity analysis are added in the rest of Figure 2. The dotted lines indicate ranges of cost-effectiveness as flight costs vary from $\$ 2,214$ to $\$ 4,500$ in Figure $2 B$, as eligibility varies from $50 \%$ to $80 \%$ in Figure $2 \mathrm{C}$, and as the distribution of patients arriving between zero and 

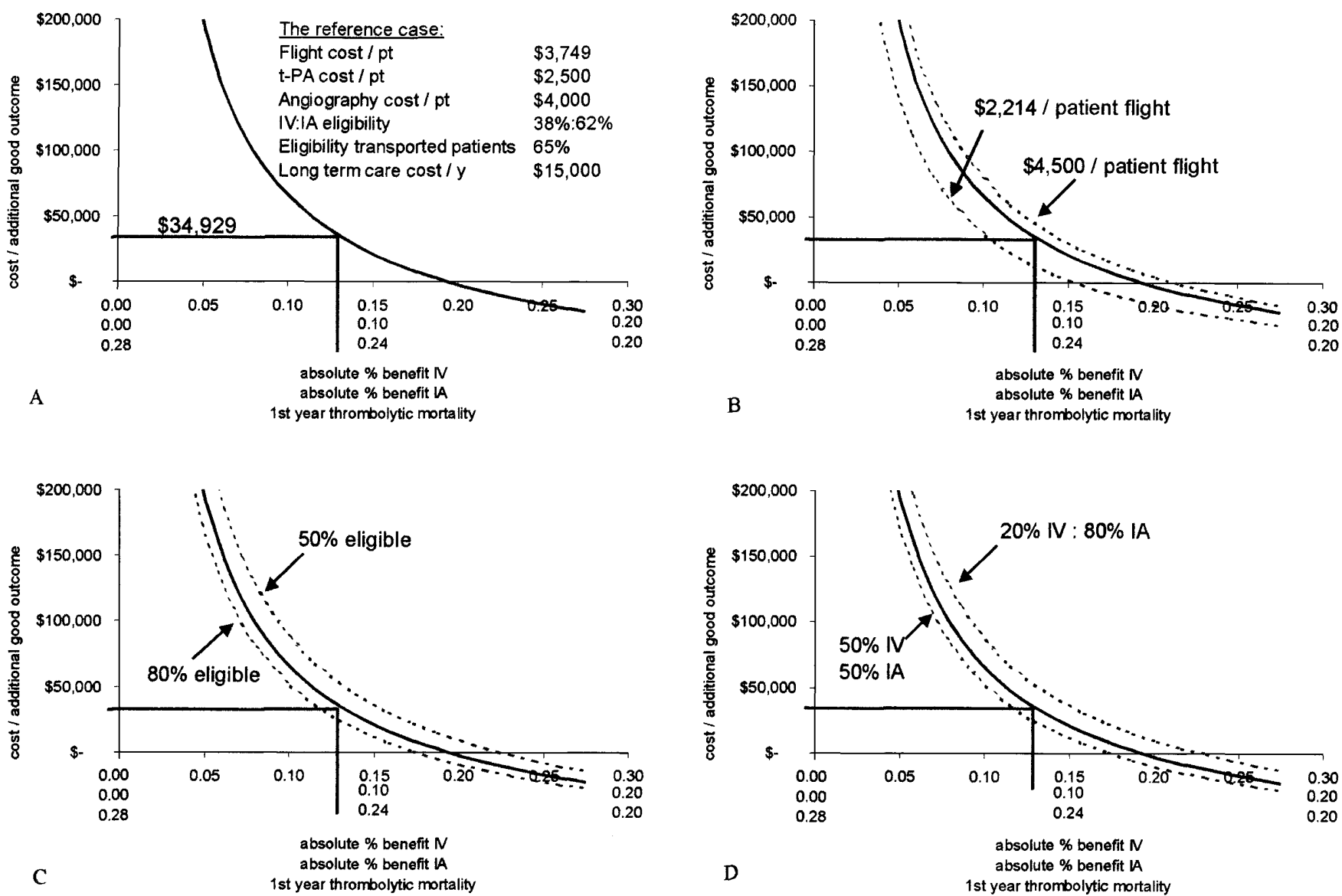

Figure 2. Sensitivity analysis of the model for cost per additional good outcome. A, Sensitivity to changes in effectiveness. The three components of effectiveness used in the model (absolute \% increase in good outcome from intravenous (IV) thrombolysis, absolute $\%$ increase in good outcome from intra-arterial (IA) thrombolysis, and absolute \% improvement in mortality) range linearly together. The horizontal and vertical plotted lines indicate the cost per additional good outcome in the reference case. B-D, The dotted lines indicate ranges of cost-effectiveness as flight costs vary from $\$ 2,214$ to $\$ 4,500$ (B), as eligibility varies from $50 \%$ to $80 \%$ (C), or as distributions of patients arriving between 0 and 3 hours for IV thrombolysis and patients arriving between 3 and 6 hours for IA thrombolysis varies (D). pt = patient; $\mathrm{t}-\mathrm{PA}=$ tissue plasminogen activator.

three hours for IV thrombolysis and patients arriving between three and six hours for IA thrombolysis varies in Figure 2D. In each case, there is some deviation in cost per additional good outcome with changes in effectiveness but little deviation through the range of other assumptions. Figure 3 shows the same sensitivity analysis for the second outcome measure, cost per QALY. The results vary little in response to changes in these assumptions.

The model was modestly sensitive to varying the assumptions regarding long-term care costs from $\$ 10,000$ to $\$ 20,000$ ( $\$ 15,000$ used in the reference case) with a median deviation in outcome of about $20 \%$ favoring the cost-effectiveness of transport for treatment as long-term care costs increased. The model was less sensitive to changes in discount rate and quality factor.

\section{DISCUSSION}

The cost-effectiveness of air medical transport of stroke patients depends on the effectiveness of avail- able therapy, but our results suggest that for a wide range of variables, the cost of helicopter transport and treatment with IV or IA thrombolytics within six hours of stroke onset is approximately $\$ 35,000$ per additional good outcome and $\$ 6,100$ per QALY. These values compare favorably with published examples suggesting that $\$ 200,000$ per additional good outcome or life saved or $\$ 50,000$ per QALY may be considered a reasonable cost in light of the benefits. ${ }^{16}$ Our results indicate helicopter use for the transport of stroke patients compares favorably with air and ground EMS transport of other patient populations. Air medical transport of trauma patients previously has been estimated to cost $\$ 2,500$ per QALY, ${ }^{12}$ and the use of advanced life support paramedic systems for cardiac arrest patients is estimated to cost $\$ 8,900$ per QALY. ${ }^{20}$ It also compares favorably with other forms of treatment for stroke prevention. The use of carotid endarterectomy for symptomatic patients has been estimated to cost $\$ 4,000$ to $\$ 50,000$ per QALY. ${ }^{16}$ Finally the cost-effectiveness of the intervention studied is well below the median cost of $\$ 42,000$ per life-year 

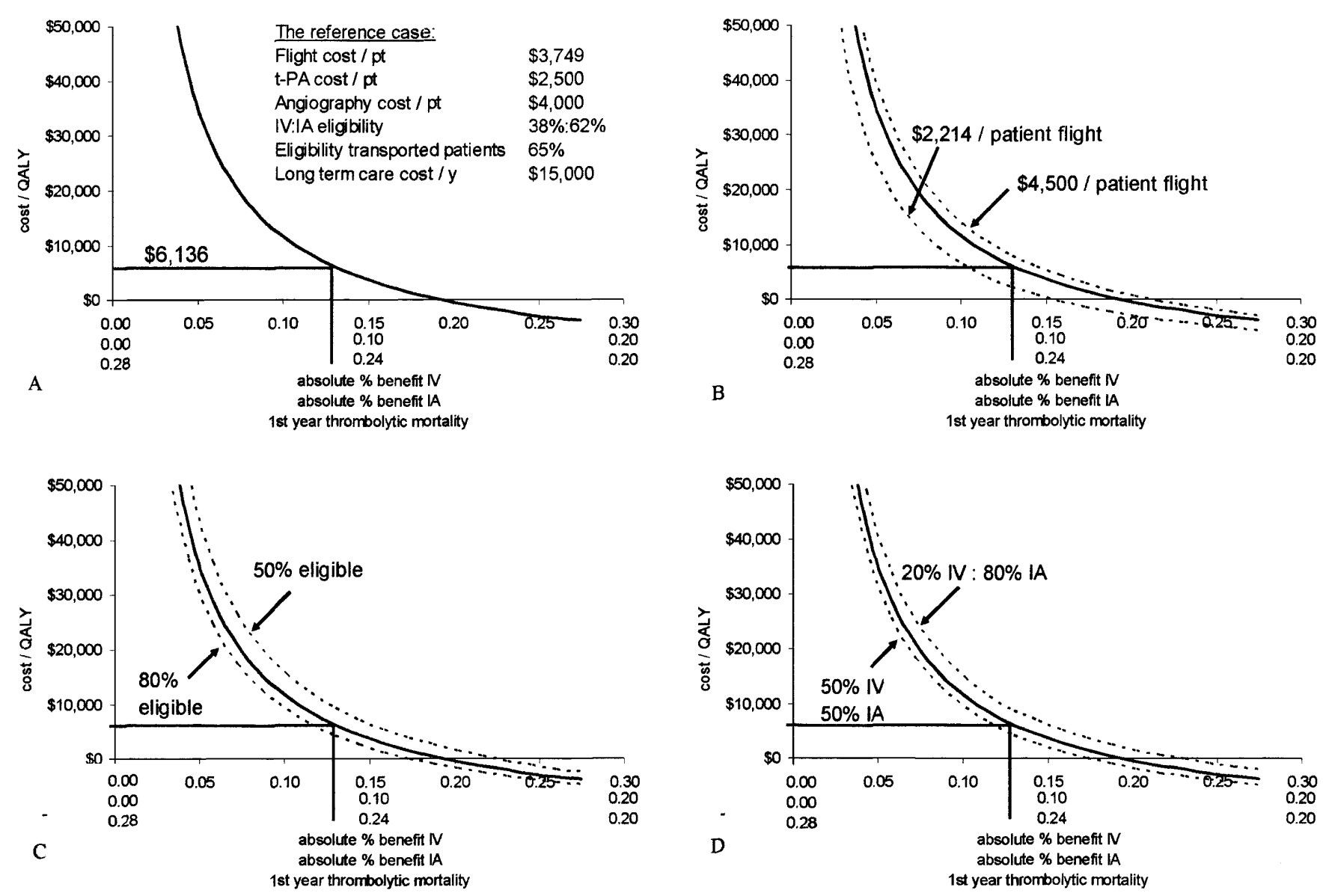

Figure 3. Sensitivity analysis of the model for cost per QALY. See Figure 2 legend for details.

identified in a compilation of cost-effectiveness analyses of 500 life-saving interventions. ${ }^{21}$

Proposals to develop specialized "stroke centers" (based on the "trauma center" model) to which patients would be diverted for acute care and rehabilitation have met with considerable controversy. The role of EMS systems in diverting patients to stroke centers is particularly unclear. Early reperfusion of ischemic brain is likely to be important, however, to obtaining the best outcome of patients with acute stroke independent of the designation of the hospital where it occurs. With or without the development of stroke centers, patients with acute strokes at hospitals without the professional or facility resources to provide optimal initial care should be transported to more appropriate facilities if that transport can be done effectively and at a reasonable cost. This model suggests that acute transports can be both, even using helicopters, a relatively expensive interhospital transport modality.

\section{LIMITATIONS}

This study evaluates the cost-effectiveness of helicopter transport of stroke patients for thrombolytic therapy, but it does not attempt to compare this mode of transport with treatment and no transport or with other modes of transportation. Rapidity of transport of stroke patients is crucial to reperfusion therapies because efficacy of treatment decreases with time even within established treatment windows. ${ }^{22}$ Some further observations are apparent: (1) Treatment at the initial hospital without transport, when possible, is inherently less expensive and more effective than transport for treatment; (2) transportation by ground is generally less expensive than by air and should be more cost-effective if it can be performed with equal or shorter transport times; and (3) the best available data suggest that transport for treatment should be performed by the quickest means available to maximize effectiveness, but there are not sufficient data yet to allow a comparison of cost-effectiveness as a function of transport times.

Several other limitations of this study must be noted. First, we did not consider the effect of treatment on length of hospital stay, which was shorter for IV t-PA patients according to the NINDS data. Had we included this factor, the cost-effectiveness of thrombolysis would have increased. Second, the perspective of this study is the total health care system, not any particular payer or provider. At current inpatient Medicare reimbursements for acute stroke (approximately $\$ 2,000-\$ 3,000$ ), the use of helicopter transport (if not separately reimbursed) to facilitate thrombolytic 
therapy could create a substantial net loss from the perspective of a tertiary care hospital no matter how cost-effective for society as a whole. Third, although the results seem robust through a wide range of assumptions regarding eligibility, there are few data regarding eligibility or the effectiveness of screening in this intervention strategy. The potential effects and costs of screening with new modalities, such as diffusionperfusion magnetic resonance imaging and xenonenhanced or perfusion computed tomography, are unknown and not included in this analysis. Finally, we need to know just how many added patients could benefit from this strategy. Previously reported data on the potential impact of air medical transport of patients with acute stroke suggested the use of helicopters may extend the geographic reach of a tertiary receiving hospital to $105 \mathrm{~km}$ (65 miles) for IV thrombolytic delivery (0-3 hours) and to $320 \mathrm{~km}$ (199 miles) for IA delivery (0-6 hours). ${ }^{23}$

\section{CONCLUSIONS}

Our analysis finds that air medical transport of acute ischemic stroke patients for thrombolysis within six hours of stroke onset is cost-effective from a broad health system perspective over a wide range of conditions and should be encouraged.

\section{References}

1. National Institute of Neurological Disorders and Stroke rt-PA Stroke Study Group. Tissue plasminogen activator for acute ischemic stroke. N Engl J Med. 1995; 333:1581-7.

2. del Zoppo G, Higashida R, Furlan A, Pessin M, Rowley H, Gent M. PROACT: a phase II randomized trial of recombinant pro-urokinase by direct arterial delivery in acute middle cerebral artery stroke. PROACT Investigators. Prolyse in Acute Cerebral Thromboembolism. Stroke. 1998; 29:4-11.

3. Furlan A, Higashida R, Wechsler L, Intra-arterial prourokinase for acute ischemic stroke: the PROACT II study: a randomized controlled trial. JAMA. 1999; 282:2003-11.

4. Kothari R, Pancioli A, Liu T, Brott T, Broderick J. Cincinnati Prehospital Stroke Scale: reproducibility and validity. Ann Emerg Med. 1999; 33:373-8.

5. Morris DL, Rosamond W, Madden K, Schultz C, Hamilton S. Prehospital and emergency department delays after acute stroke: the Genentech Stroke Presentation Survey. Stroke. 2000; 31:2585-90.
6. Kothari R, Barsan W, Brott T, Broderick J, Ashbrock S. Frequency and accuracy of prehospital diagnosis of acute stroke. Stroke. 1995; 26:937-41.

7. Schroeder EB, Rosamond WD, Morris DL, Evenson KR, Hinn AR. Determinants of use of emergency medical services in a population with stroke symptoms: the Second Delay in Accessing Stroke Healthcare (DASH II) Study. Stroke. 2000; 31:2591-6.

8. Rapid identification and treatment of acute stroke. In: $\mathrm{NIH}$ Consensus Conference. Crystal City, VA, 1997.

9. Alberts MJ, Hademenos G, Latchaw RE, et al. Recommendations for the establishment of primary stroke centers. Brain Attack Coalition. JAMA. 2000; 283:3102-9.

10. Chalela J. Safety of air medical transportation after tissue plasminogen activator administration in acute ischemic stroke. Stroke. 1999; 30:2366-8.

11. Conroy M, Rodriguez S, Kimmel S, Kasner S. Helicopter transfer offers a potential benefit to patients with acute stroke. Stroke. 1999; 30:2580-4.

12. Gearhart P, Wuerz R, Localio A. Cost-effectiveness analysis of helicopter EMS for trauma patients. Ann Emerg Med. 1997; 30:500-6.

13. Silbergleit $\mathrm{R}$, Blumstein H. Revascularization options: implications for critical transport. Acad Emerg Med. 1995; 2:568-9.

14. Fagan S, Morgenstern L, Petitta A, et al. Cost-effectiveness of tissue plasminogen activator for acute ischemic stroke. NINDS rt-PA Stroke Study Group. Neurology. 1998; 50:883-90.

15. Siegel J, Weinstein M, Russell L, Gold M. Recommendations for reporting cost-effectiveness analyses. Panel on Cost-Effectiveness in Health and Medicine. JAMA. 1996; 276:1339-41.

16. Holloway R, Benesch C, Rahilly C, Courtright C. A systematic review of cost-effectiveness research of stroke evaluation and treatment. Stroke. 1999; 30:1340-9.

17. Kidwell CS, Starkman S, Eckstein M, Weems K, Saver JL. Identifying stroke in the field: prospective validation of the Los Angeles prehospital stroke screen (LAPSS). Stroke. 2000;31:71-6.

18. Derdeyn C, Powers W. Cost-effectiveness of screening for asymptomatic carotid atherosclerotic disease. Stroke. 1996; 27:1944-50.

19. Porsdal V, Boysen G. Costs of health care and social services during the first year after ischemic stroke. Int J Technol Assess Health Care. 1999; 15:573-84.

20. Valenzuela TD, Criss EA, Spaite D, Meislin HW, Wright AL, Clark L. Cost-effectiveness analysis of paramedic emergency medical services in the treatment of prehospital cardiopulmonary arrest. Ann Emerg Med. 1990; 19:1407-11.

21. Tengs TO, Adams ME, Pliskin JS, et al. Five hundred life-saving interventions and their cost-effectiveness. Risk Anal. 1995; 15:369-90.

22. Marler JR, Tilley BC, Lu M, et al. Early stroke treatment associated with better outcome: the NINDS rt-PA stroke study. Neurology. 2000; 55:1649-55.

23. Scott P, Temovsky C, Lawrence K, Gudaitis E, Lowell M. Analysis of Canadian population with potential access to intravenous thrombolysis for acute ischemic stroke. Stroke. 1998; 29:2304-10. 


\section{APPENDIX}

$$
\begin{gathered}
\frac{\mathrm{COST}}{\mathrm{AGO}}=\frac{\text { Total flight costs }+ \text { total treatment costs }+ \text { total LTCC }}{\mathrm{AE}_{\mathrm{TX}}} \\
\frac{\mathrm{COST}}{\mathrm{QALY}}=\frac{\text { Total flight costs }+ \text { total treatment costs }+ \text { total LTCC }}{\mathrm{QALY}_{\mathrm{TX}}-\mathrm{QALY}_{\mathrm{NT}}} \\
\text { Total flight costs }=\mathrm{FC} \cdot \frac{1}{\mathrm{E}}
\end{gathered}
$$

Total treatment costs $=\left[\mathrm{PT}_{\mathrm{IV}} \cdot \mathrm{DC}\right]+\left[\mathrm{PT}_{\mathrm{IA}} \cdot(\mathrm{DC}+\mathrm{AC})\right]$

Total LTCC $=$ Discounted LTCC $_{\mathrm{TX}}-$ discounted LTCC $_{\mathrm{NT}}$

$$
\begin{gathered}
\text { Discounted } \mathrm{LTCC}_{\mathrm{TX}}=\sum_{\mathrm{i}=1}^{\mathrm{LY}_{\mathrm{TX}}} \frac{\mathrm{LTCC} \cdot\left(1-\mathrm{AE}_{\mathrm{TX}}\right)}{(1+\mathrm{D})^{\mathrm{i}}} \\
\text { Discounted } \mathrm{LTCC}_{\mathrm{NT}}=\sum_{\mathrm{i}=1}^{\mathrm{LY}_{\mathrm{NT}}} \frac{\mathrm{LTCC}}{(1+\mathrm{D})^{\mathrm{i}}} \\
\mathrm{LY}_{\mathrm{X}}=1+\left(1-\mathrm{FYM}_{\mathrm{X}} / \mathrm{AM}_{\mathrm{X}}\right) \\
\mathrm{AE}_{\mathrm{TX}}=\left(\mathrm{PT}_{\mathrm{IV}} \cdot \mathrm{AE}_{\mathrm{IV}}\right)+\left(\mathrm{PT}_{\mathrm{IA}} \cdot \mathrm{AE}_{\mathrm{IA}}\right) \\
\mathrm{QALY}_{\mathrm{TX}}=\mathrm{LY}_{\mathrm{TX}} \cdot\left[\left(\mathrm{AE}_{\mathrm{TX}}+\mathrm{GO}\right)+\left(1-\mathrm{GO}-\mathrm{AE}_{\mathrm{TX}}\right) \cdot \mathrm{Q}\right] \\
\mathrm{QALY}_{\mathrm{NT}}=\mathrm{LY}_{\mathrm{NT}} \cdot[(\mathrm{GO})+(1-\mathrm{GO}) \cdot \mathrm{Q}]
\end{gathered}
$$

COST $=$ total system cost

$\mathrm{AGO}=$ additional good outcomes

QALY = quality-adjusted life year

$\mathrm{FC}=$ flight costs (per transport)

$\mathrm{E}=$ eligibility (\% of transported patients)

$\mathrm{PT}_{\mathrm{X}}=$ percent treated by route $\mathrm{X}$

$\mathrm{DC}=$ drug cost

$\mathrm{AC}=$ angiography cost

$\mathrm{FYM}_{\mathrm{X}}=$ first-year mortality with treatment $\mathrm{X}$

$\mathrm{AM}_{\mathrm{X}}=$ annual mortality with treatment $X$ after

first year

LTCC $=$ long-term care costs per year

$\mathrm{D}=$ discount rate

$\mathrm{LY}_{\mathrm{X}}=$ life-years remaining with treatment $\mathrm{X}$

$\mathrm{AE}_{\mathrm{X}}=$ absolute percent effect with

treatment $X$

$\mathrm{GO}=$ percent with good outcomes

without treatment

$\mathrm{Q}=$ quality factor

$\mathrm{tPA}=$ thrombolytic group

$\mathrm{IV}=$ intravenous route

$\mathrm{IA}=$ intra-arterial route

$\mathrm{TX}=$ treatment

$\mathrm{NT}=$ no treatment 